\title{
Development of a Stochastic Hourly Solar Irradiation Model
}

\author{
Kristijan Brecl and Marko Topič \\ Faculty of Electrical Engineering, University of Ljubljana, Tržaška 25, 1000 Ljubljana, Slovenia \\ Correspondence should be addressed to Kristijan Brecl; kristijan.brecl@fe.uni-lj.si
}

Received 27 May 2013; Revised 28 October 2013; Accepted 4 January 2014; Published 17 February 2014

Academic Editor: Niyaz Mohammad Mahmoodi

Copyright (C) $2014 \mathrm{~K}$. Brecl and M. Topič. This is an open access article distributed under the Creative Commons Attribution License, which permits unrestricted use, distribution, and reproduction in any medium, provided the original work is properly cited.

\begin{abstract}
We have developed a new solar irradiation model and implemented it in the SunIrradiance photovoltaic cell/module simulator. This model uses stochastic methods to generate the hourly distribution of solar irradiation on a horizontal or inclined surface from monthly irradiation values on the horizontal surface of a selected location and was verified with the measured irradiance data in Ljubljana, located in Central Europe. The new model shows better simulation results with regard to the share of the diffuse irradiation in the region than the other models. The simulation results show that the new solar irradiation model is excellent for photovoltaic system simulations of single junction PV technologies.
\end{abstract}

\section{Introduction}

The research of photovoltaic (PV) flat plate technology requires the simulations of all PV devices from solar cells [1] to PV modules. On the solar cell level, the irradiance data are not a crucial parameter, since the standard AM1.5 spectrum normalized to the total intensity of $1000 \mathrm{~W} / \mathrm{m}^{2}$ [2] is used to evaluate the solar cell's performance. The same AM1.5 spectrum is normally used for the simulations of PV modules. Also, the output power of a fabricated PV module is declared with the AM1.5 spectrum under standard test conditions (STC) [3]. But when PV modules or PV systems are simulated and evaluated under real outdoor conditions [4], the STC have to be upgraded to outdoor conditions (OC). This demands a suitable solar irradiation model that simulates the real hourly solar irradiation $\left(H_{h}\right)$ reliably. Although the spectral information of the light source is very appreciated during the characterisation procedure of solar cells and PV modules, it has less importance in the PV system simulations. The spectral information in OC is relevant only if thin-film multijunction solar cells are used. Otherwise, the hourly values of (direct and diffuse) irradiation data are sufficient to simulate the performance of a PV module or system.

Several spectral irradiance and irradiation models have been developed during the last two or three decades $[5,6]$, but most of them cover only the clear sky conditions. The models differ with regard to their complexity or the number of input parameters. The simplest ASHRAE model [6] is based on the empirically defined parameters and does not use any weather parameters, while the Bird [5] or REST2 [7] models use 6 or 8 atmospheric parameters to calculate the clear-sky irradiance. A good comparison between 18 clear-sky irradiance models was made by Gueymard [6]. The quality of a model does not directly correlate with the number of input parameters, but from Gueymard's comparison we can conclude that the models with less than 2 atmospheric input parameters are simple but more location dependent and therefore unreliable for universal use.

The modelling of the cloudy sky irradiance $[8,9]$ is very difficult and is more related to local weather conditions.

In our in-house developed solar cell and PV module simulation program named SunIrradiance, we use the standard AM1.5 spectrum for the STC simulations or the Bird [5] spectral irradiance model upgraded for the cloudy sky conditions (BirdUpg) when outdoor conditions are analysed. As cloudy sky conditions were modelled only for a few places in Slovenia, we were seeking for a more universal irradiation model. The commercially available irradiation simulators like Meteonorm cannot be integrated in our simulation program and due to the interpolation of the input parameters usually cannot simulate solar irradiation for Slovenia truthfully. They 
normally can simulate the global irradiation, but they exhibit an error when the information on the diffuse light is needed. In this paper we are presenting a new, recently developed solar irradiation model (SISIM) for inclined surfaces where only the monthly values of solar irradiation are used as an input.

\section{New Solar Irradiation Model SISIM for Horizontal Surfaces}

SunIrradiance was developed to simulate the behaviour of solar cells and PV modules under STC or any real outdoor conditions [10]. The program uses the one-diode model to simulate the $I V$ characteristics of the solar cell:

$$
I_{c}=I_{\mathrm{ph}}-I_{0} \cdot\left(e^{\left(V_{c}+R_{s} \cdot I_{c}\right) / V_{T}}-1\right)-G_{\mathrm{sh}} \cdot\left(V_{c}+R_{s} \cdot I_{c}\right),
$$

where $V_{c}$ and $I_{c}$ are solar cell's voltage and current, $R_{s}$ and $G_{\mathrm{sh}}$ are series and shunt resistances, and $I_{0}$ and $I_{\mathrm{ph}}$ are the saturation current and the photocurrent of the cell, respectively. The $I_{\mathrm{ph}}, R_{s}$, and $G_{\mathrm{sh}}$ are irradiance dependent; $I_{0}$ and $I_{\mathrm{ph}}$ are temperature dependent parameters. In case of the BirdUpg model, the photocurrent is calculated from the modelled spectral irradiance model taking into account the energy gap limit of the cell. When the new SISIM model is used, the photocurrent is calculated simply by dividing the cell's $I_{\mathrm{ph}}$ current at STC with $1000 \mathrm{~W} / \mathrm{m}^{2}$ and multiplying it by the simulated irradiance value.

In the current SunIrradiance BirdUpg model, the cloudiness over a year is modelled empirically from the measured irradiance values over the last decade in Slovenia by changing the aerosol optical depth (AOD). The new irradiation model for inclined surfaces is based on the average monthly global irradiation $\left(H_{m}\right)$ values derived from the recently developed and published Slovenian horizontal global solar irradiation database [11]. The global horizontal irradiation $(H)$ was modelled with the help of 10-year measuring of the global and diffuse irradiation at 7 meteorological stations in Slovenia and additional 19 meteorological stations with the measurement of $H$ values only.

2.1. The Model. The SISIM is based on the averaged $H_{m}$. As the simulation of PV modules with the monthly irradiation values only is not sufficient, hourly values should be generated with the use of the stochastic models. Hourly values are obtained in two steps. First daily irradiation values $\left(H_{d}\right)$ are calculated for each month and then the hourly irradiation values $\left(H_{h}\right)$ are derived. The statistical properties of the intermediate (daily) and final (hourly) simulated data must be the same as from the input data. To ensure the repeatability of the calculations, the same random seed is used. Prerequisite data for the calculation of the solar irradiation limits and clearness indexes $K_{t}$ are the calculated theoretical maximum horizontal irradiation $\left(H_{0}\right)$ and the clear sky irradiation of the selected location. The $H_{0}$ is calculated from the extraterrestrial solar irradiation $\left(1367 \mathrm{~W} / \mathrm{m}^{2}\right)$ multiplied by the cosine of the incident angle for the given location and time. The clear sky irradiation for the selected location can be calculated with the Heliosat-1 [6] or Ineichen [12] model.
The $H_{d}$ values are calculated by the use of the Markov transition matrices MTM [13]. The methodology for the calculation of the daily clearness index $K_{t, d}$ was first presented by Aguiar et al. [13] and used with changed matrices in Meteonorm [14]. The MTM method assumes a correlation between the irradiation values of consecutive days. It consists of $910 \times 10$ matrices for the monthly clearness index from 0.1 to 1.0 in a step of 0.1 . The $K_{t, d}$ of the previous day defines the row of the matrix. Afterwards, the values in the row are summed up to the column when the sum is greater than a random number defined by a generator with a uniform distribution between 0 and 1 . The actual clearness index for the day $K_{t, d}$ is then defined as a linear interpolation of the interval [13]. The daily clearness index $K_{t, d}$ in the simulation procedure is limited between 0.05 and 1.0, absolutely, with a maximum overshot of $5 \%$ over the clear sky clearness index. On a monthly basis the average $K_{t, d}$ must not deviate from the monthly value by more than $1 \%$. Finally the daily irradiation values are scaled to fit the monthly input values.

After the successful daily irradiation routine, an hourly irradiation routine takes place. A time-dependent, autoregressive, Gaussian model (TAG) [15] for calculating the synthetic $H_{h}$ is used for the simulation of $H_{h}$. In the TAG model, first the estimated hourly clearness index $K_{d h}$ is calculated from the clear sky values:

$$
K_{d h}=H_{h, c} \cdot \frac{H_{d}}{H_{d, c}},
$$

where $H_{h, c}, H_{d}$, and $H_{d, c}$ are global hourly clear-sky, daily, and daily clear-sky irradiation values, respectively. The actual hourly clearness index $K_{t, h}$ is defined as

$$
K_{t, h}=K_{d h}+y \cdot \sigma
$$

with

$$
y(h)=\emptyset \cdot y(h-1)+r
$$

where $\emptyset$ is a first-order autocorrelation, $\sigma$ is the standard deviation, and $r$ is the normally distributed random variable.

The functions are defined in accordance with the Aguiar and Collares-Pereira [15] and METEONORM [14]. Similar to the daily irradiation procedure, the hourly irradiation procedure also has some general restrictions. The hourly clearness index $K_{t, h}$ can be up to $5 \%$ greater than the clear sky index. To avoid irregular values in the morning and evening hours the $K_{t, h}$ is limited to 0.8 for solar zenith angles over $80^{\circ}$. The hourly procedure is repeated until the daily sum of the $H_{h}$ values deviates from the $H_{d}$ value by less than $1 \%$.

By multiplying the hourly clearness index $K_{t, h}$ by $H_{0}$, the solar irradiation on a horizontal plane is defined. To calculate the irradiation on an inclined surface $\left(H_{\text {poa }}\right)$, the information of the diffuse part of the light $\left(H_{\text {dif }}\right)$ is needed. In our SunIrradiance simulation program three diffuse models are incorporated: Maxwell [16], Louche [17], and Reindl$2[18,19]$. While the Maxwell and the Reindl-2 models need additional information of the air mass value and solar elevation angle, respectively, the Louche model uses only the 
information of the clearness index and extraterrestrial irradiation. All three models showed more or less good simulation results on a yearly basis during the validation procedure for Ljubljana, but the deviations of the monthly irradiation diffuse fractions were too high. Therefore we additionally implement a modified Louche model in SunIrradiance. The modifications were made on the polynomial fit of the direct $\left(H_{\text {dir }}\right)$ to $H_{0}$ ratio. The new polynomial fit was made on the basis of the diffuse and global irradiance measurements in Ljubljana between 2008 and 2011.

Louche

$$
\begin{aligned}
\frac{H_{\text {dir }}}{H_{0}}= & -10.627 \cdot K_{t, h}^{5}+15.307 \cdot K_{t, h}^{4} \\
& -5.205 \cdot K_{t, h}^{3}+0.994 \cdot K_{t, h}^{2}-0.059 \cdot K_{t, h}+0.002 .
\end{aligned}
$$

Poly. fit

$$
\begin{aligned}
\frac{H_{\mathrm{dir}}}{H_{0}}= & -6.969 \cdot K_{t, h}^{5}+8.075 \cdot K_{t, h}^{4}-0.321 \cdot K_{t, h}^{3} \\
& -0.313 \cdot K_{t, h}^{2}+0.034 \cdot K_{t, h}+0.001 .
\end{aligned}
$$

In Figure 1(a) the Louche fit and our polynomial fit to the measured values are presented. Both curves are very similar to a little higher values when the Louche model is used. Since the monthly deviations of the simulated $H_{\text {dif }}$ from the measured ones were still too high, we decided to split the polynomial $H_{\text {dir }} / H_{0}$ fit into four equations-one for each season. The equations of the seasonal polynomial fits are winter

$$
\begin{aligned}
\frac{H_{\mathrm{dir}}}{H_{0}}= & -10.001 \cdot K_{t, h}^{5}+12.090 \cdot K_{t, h}^{4}-2.082 \cdot K_{t, h}^{3} \\
& -0.099 \cdot K_{t, h}^{2}+0.029 \cdot K_{t, h}+0.001,
\end{aligned}
$$

spring

$$
\begin{aligned}
\frac{H_{\mathrm{dir}}}{H_{0}}= & -13.257 \cdot K_{t, h}^{5}+20.234 \cdot K_{t, h}^{4}-8.317 \cdot K_{t, h}^{3} \\
& +1.669 \cdot K_{t, h}^{2}-0.113 \cdot K_{t, h}+0.001,
\end{aligned}
$$

summer

$$
\begin{aligned}
\frac{H_{\mathrm{dir}}}{H_{0}}= & 0.017 \cdot K_{t, h}^{5}-5.002 \cdot K_{t, h}^{4}+7.892 \cdot K_{t, h}^{3} \\
& -2.242 \cdot K_{t, h}^{2}+0.185 \cdot K_{t, h}+0.001,
\end{aligned}
$$

autumn

$$
\begin{aligned}
\frac{H_{\mathrm{dir}}}{H_{0}}= & 2.162 \cdot K_{t, h}^{5}-7.313 \cdot K_{t, h}^{4}+8.519 \cdot K_{t, h}^{3} \\
& -2.255 \cdot K_{t, h}^{2}+0.165 \cdot K_{t, h}+0.001 .
\end{aligned}
$$

The seasonal curves are presented in Figure 1(b). With these four equations we could obtain a very good fit to the real diffuse fractions in the monthly solar irradiations.
2.2. Verification of the SISIM. The new irradiation model SISIM was verified using a step-by-step procedure from the final global-to-diffuse irradiation step back to the first daily clearness index calculation step. Since long-term data are not needed for the model verification, we used global and diffuse irradiation data measured during the last three years in Ljubljana, Slovenia, with the annual share of the diffuse irradiation between 40 and 50\%. The solar irradiation conditions in Ljubljana are similar to those of other locations in Central Europe.

The global-to-diffuse irradiation procedure is one of the most critical modelling parts. The procedure works fine with the averaged solar irradiation data, but with the real measured one-year data the deviations are larger since the used diffuse model is based empirically on the long-term data and cannot predict deviations of the atmospheric parameters. As it can be seen from the left-hand graph in Figure 1, the measured $H_{\text {dir }} / H_{0}$ values deviate from the fitted one. The verification of the global-to-diffuse step was made by using the measured $H_{h}$ as an input. The measured and simulated monthly-diffuse to-global irradiation ratios in the year 2011 in Ljubljana are presented in Figure 2.

In case of Ljubljana it can be seen from Figure 2 that simulations are in good agreement with the measurements over the whole year, even though the share of the diffuse irradiation deviates from the expected cosine curve (summer months and November) in the observed year. The average deviation of the simulated data is $+3 \%$ with the maximum monthly deviations of $+12 \%$ in March and $-6 \%$ in July, relatively. The error of the diffuse-to-global irradiation ratio on a yearly basis is $+0.3 \%$, absolutely. Other simulated years in case of Ljubljana show even smaller monthly deviations.

The verification of the daily-to-hourly irradiation procedure was made by using the measured $H_{d}$ as an input and checking the final simulated $H_{h}$ after the global-to-diffuse irradiation step with the measured $H_{h}$ including also the uncertainty of the global-to-diffuse step. The relative deviation of the simulated $H_{h}$ values compared to the measured ones is presented in Figure 3.

The average deviation of the simulated $H_{h}$ values is $-1.5 \%$, relatively, while the absolute deviation stays mostly below 3$4 \%$, which confirms the quality of the model.

The verification of the monthly-to-daily irradiation procedure is irrelevant since the model allows a $1 \%$ deviation of the monthly values which is at the end eliminated by scaling the daily values to fit the input $H_{m}$.

The histogram of $H_{h}$ makes another good comparison of different simulation models and measurements. A histogram directly compares the dynamics of the hourly averaged solar irradiance over the whole year. Figure 4 shows the histogram of the measured and simulated horizontal annual solar energy distribution in Ljubljana. The measured values were averaged over the period between 2008 and 2011. For the comparison we add also the results from the Meteonorm 7 (MN7) [14, 20] commercial simulation software for Ljubljana.

The comparison of distribution profiles (Figure 4(a)) shows that both simulation models (SISIM and MN7) overpredict cloudier days $\left(G<300 \mathrm{~W} / \mathrm{m}^{2}\right)$. The $M N 7$ also 


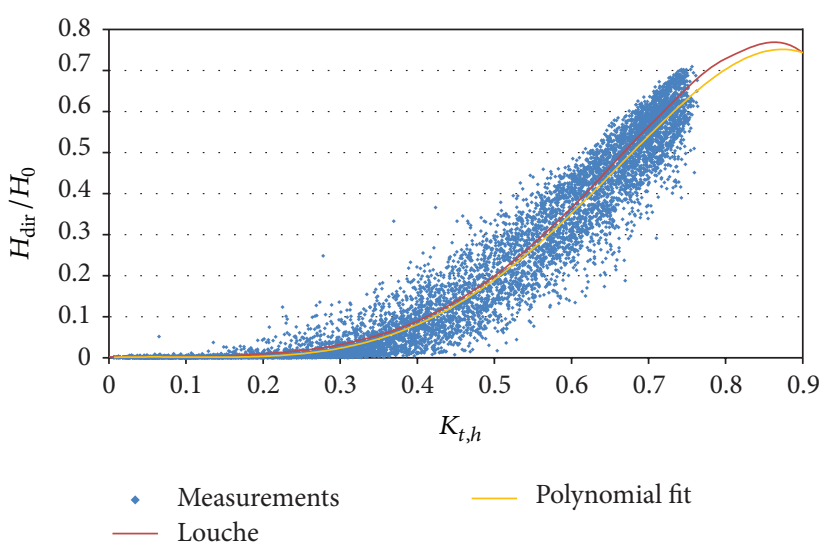

(a)

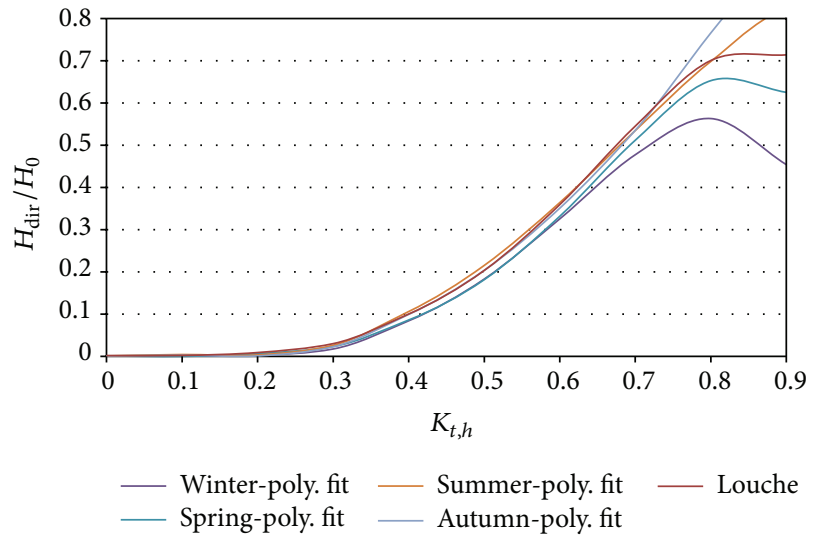

(b)

FIGURE 1: Modified seasonal curves of the global-to-diffuse irradiance Louche model (measurements in Ljubljana 2008-2011).

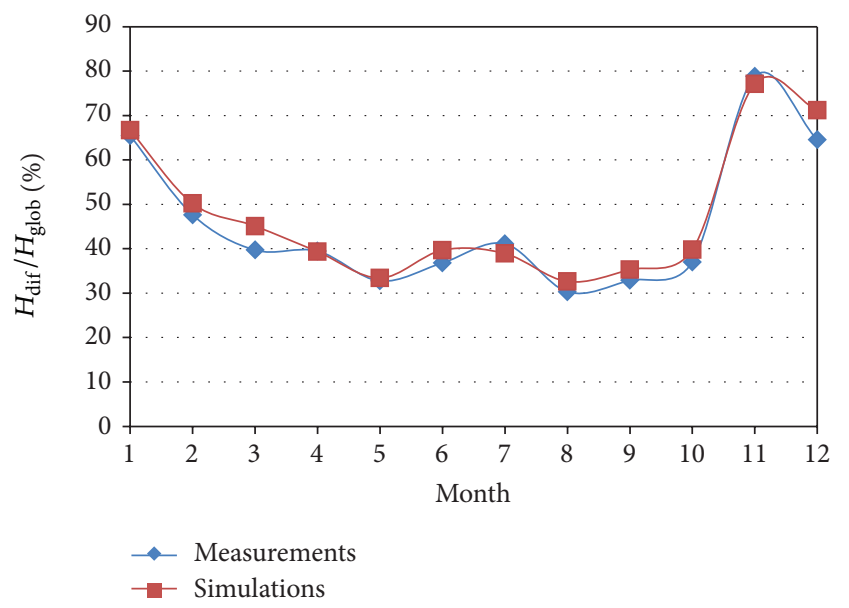

FIGURE 2: Monthly diffuse-to-global irradiation ratio in 2011.

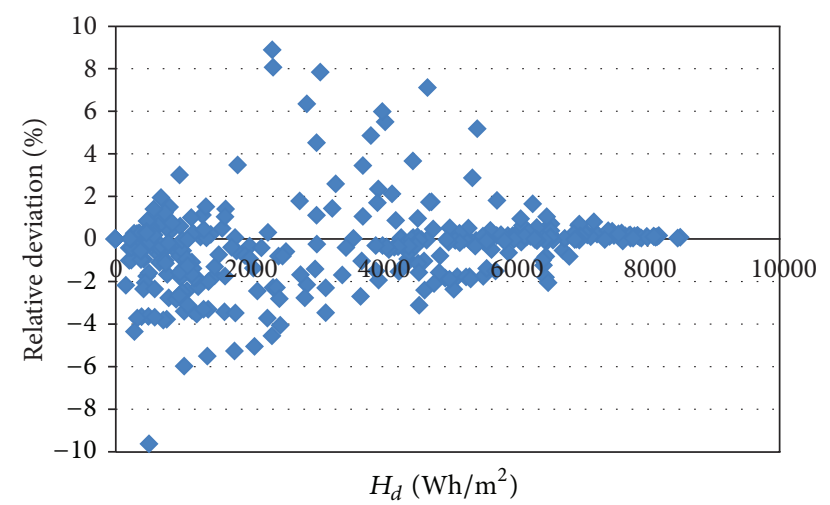

Figure 3: Verification of the daily-to-hourly irradiation step for Ljubljana.

overpredicts the partially cloudy days $\left(300<G<500 \mathrm{~W} / \mathrm{m}^{2}\right)$, while the SISIM deviates at very clear sky conditions. Figure 4(b) shows the simulated solar energy distribution with the BirdUpg and the new SISIM model. The BirdUpg largely overpredicts the irradiation in the middle range of the irradiance levels and stops at irradiance values of $900 \mathrm{~W} / \mathrm{m}^{2}$.

\section{Solar Irradiation on the Inclined Surfaces}

A solar irradiation model is not useful for simulations unless it calculates the irradiation on the inclined surfaces. In SunIrradiance we use the most used and cited Perez et al. [21] model for the calculation of the in-plane irradiation. The irradiation on an inclined surface $H_{\text {poa }}$ is defined as

$$
\begin{aligned}
H_{\text {poa }}= & H_{\text {direct }}+H_{\text {isotropic }}+H_{\text {circumsolar }} \\
& +H_{\text {horizontal ribbon }}+H_{\text {ground reflected }}, \\
H_{\text {poa }}= & \frac{H_{b}}{\cos \theta_{z}} \cos \theta+H_{\text {dif }}\left(1-F_{1}\right) \frac{1+\cos \beta}{2} \\
& +H_{\text {dif }} F_{1} \frac{\cos \theta}{\cos \theta_{z}}+H_{\text {dif }} F_{2} \sin \beta+H \rho \frac{1-\cos \beta}{2},
\end{aligned}
$$

where $H_{b}, H_{\text {dif }}$, and $H$ are direct (beam), diffuse, and global irradiation on the horizontal surface, respectively; $F_{1}$ and $F_{2}$ are coefficients expressing the degree of circumsolar and horizon/zenith anisotropy; $\theta, \theta_{z}$, and $\beta$ are the angle of incidence, the zenith angle, and the surface inclination angle.

The verification was made similarly as in the other steps with the input values of the hourly diffuse and direct irradiation. In case of Ljubljana and a south oriented surface with an inclination angle of $30^{\circ}$ (Figure 5), the simulations deviate from the measured values for around $\pm 10 \%$, relatively, except for irradiations below $200 \mathrm{Wh} / \mathrm{m}^{2}$ where the deviations are up to $40 \%$. The average deviation is zero. Higher uncertainties at lower irradiations $\left(<200 \mathrm{Wh} / \mathrm{m}^{2}\right)$ are mostly due to higher zenith angles where also the uncertainty of the measured values is higher due to the uncertainties of the pyranometer.

3.1. Solar Irradiation Maps. The use of the Slovenian global horizontal irradiation database [11] with a grid of around $1 \mathrm{~km}$ allows us to plot in-plane irradiation maps for any orientation 


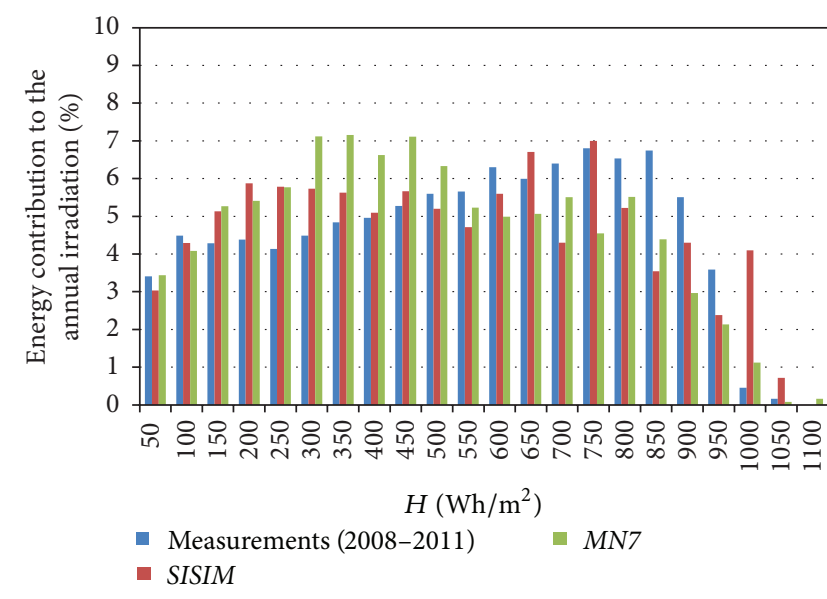

(a)

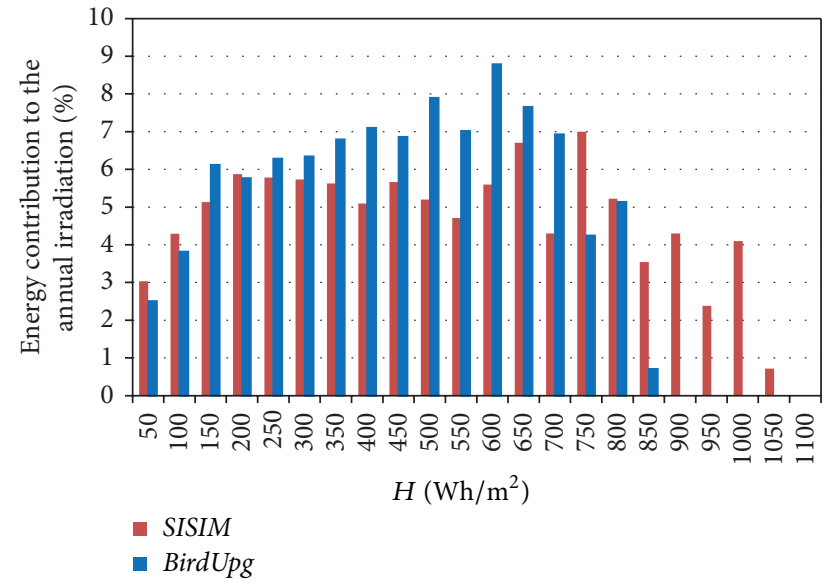

(b)

FIGURE 4: Simulated and averaged measured distribution of the horizontal annual solar energy in Ljubljana (a) and SISIM versus BirdUpg model (b).

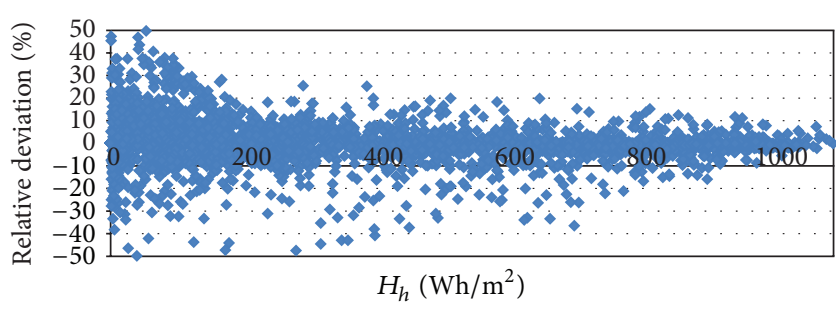

FIGURE 5: Verification of the in-plane irradiation model (orientation: south, inclination: $30^{\circ}$ ).

and inclination angle of a PV module in Slovenia. In Figure 6, irradiation maps for the horizontal and the south oriented surface with an inclination angle of $30^{\circ}$ is presented.

\section{Simulations of the PV Module Performance}

The simulation of a PV system always starts on the PV module level. In a PV system the module results are then simply multiplied by the number of modules in a PV array and further connected to an inverter. The PV system's performance is then simulated straight forward by adding the DC cabling losses, inverter performance, and AC cabling losses.

In this paper we will limit our presentation to a simulation of the energy output of a single $230 \mathrm{~W}$ PV module made of 60 multicrystalline solar cells. The parameters of the onediode model (see Section 2) of the PV module were derived from the measured $I V$ curves under STC and different weather conditions. The ambient temperature $T_{\text {air }}$ is taken from the monthly averaged long-term temperatures and average daily temperature deviations in Ljubljana. The data are obtained from the Slovenian Meteorological Agency [22]. The daily ambient temperature variation is defined as a linear change with the lowest value at sunrise and the highest value in the middle of the noon-sunset time interval. The module temperature $T_{\text {module }}$ is calculated from and in-plane irradiation $H_{\text {poa }}$ as

$$
T_{\text {module }}=T_{\text {air }}+0.03\left[{ }^{\circ} \mathrm{C} \cdot \mathrm{m}^{2} / \mathrm{Wh}\right] \cdot H_{\mathrm{poa}} \cdot
$$

The annual energy production of the modelled PV module with an inclination angle of $30^{\circ}$ and south orientation was simulated with the BirdUpg model [5] and with the new SISIM model. Both simulation results are presented in Figure 7.

The energy yield of the module using BirdUpg and SISIM is $1296 \mathrm{Wh} / \mathrm{Wp}$ and $1244 \mathrm{Wh} / \mathrm{Wp}$, respectively. As it can be seen from Figure 7, the BirdUpg model gives a more smooth energy distribution over a year while the SISIM simulates the real irradiation better with higher irradiance intensity deviations over a year.

From the simulation results we can conclude that the SISIM simulates the daily and monthly variations more realistically than the BirdUpg spectral irradiance model. The new model is a good tool for the simulation of PV systems where the daily variations are important when simulating inverter and cabling losses. The new irradiation model together with the Slovenian irradiation database gives the possibility to simulate the PV system performance at any location in Slovenia and not only at a limited number of places where weather data of cloudiness are available. On the contrary, the spectral irradiance model is still necessary for the simulation of PV modules made of multijunction solar cells where the spectral information of the irradiance is needed for accurate energy prediction.

\section{Conclusion}

A new solar irradiation model was developed for Slovenia and Central Europe. The model calculates the hourly solar irradiation on an inclined surface from the known monthly horizontal global irradiation data. The new model together 


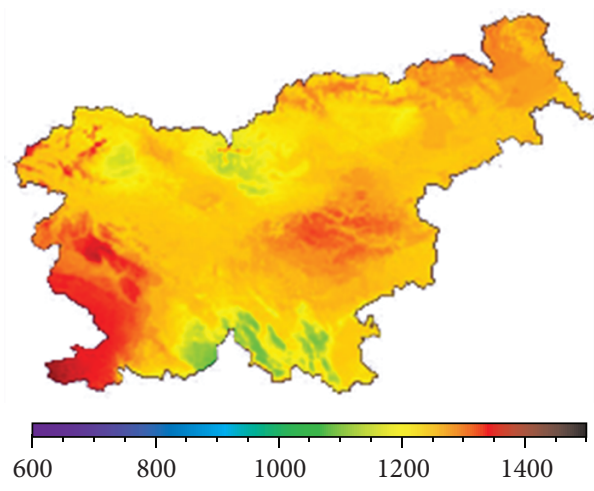

(a)

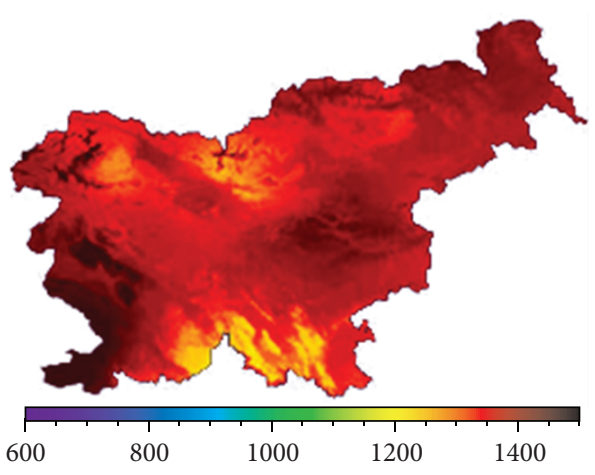

(b)

FIGURE 6: Simulated annual solar irradiation (kWh/year) on the horizontal surface (a) and the south oriented surface with an inclination angle of $30^{\circ}$ (b) (the values in the legend are in $\mathrm{kWh} / \mathrm{m}^{2}$ ).

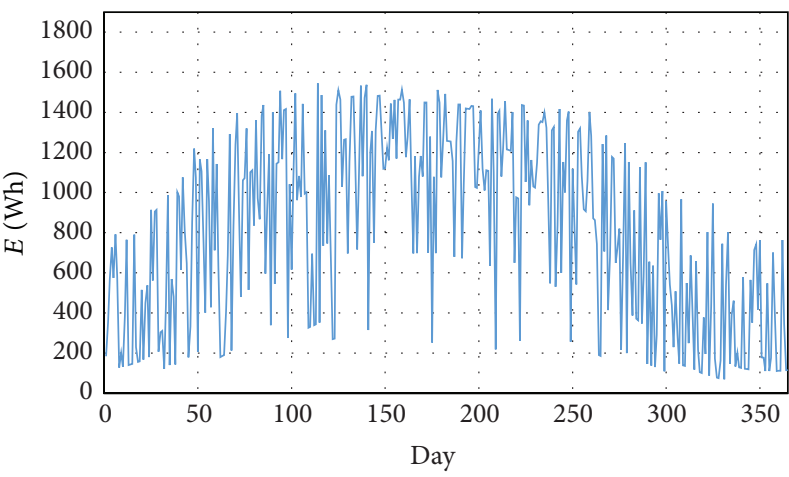

(a)

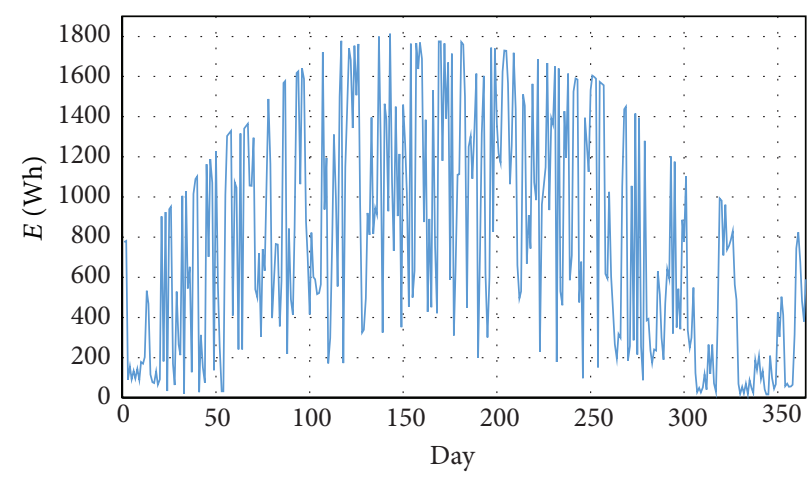

(b)

FIGURE 7: Hourly energy output of a $230 \mathrm{~W}$ multicrystalline silicon PV module using BirdUpg (a) and SISIM (b).

with the Slovenian irradiation database gives the best possibility to simulate the solar irradiation in the region.

The model uses stochastic models to generate hourly values from the monthly global irradiation values on the horizontal surface. With the help of the measured diffuse and global solar irradiation data in Slovenia, the global-to-diffuse irradiation calculation step was modified. In the SISIM, seasonal polynomial fits of the diffuse-to-extraterrestrial irradiation ratios are used and are in very good agreement with the measurements. In total, the new SISIM exhibits an average simulation error of the horizontal solar irradiation of a few percents.

The new solar irradiation model is implemented in our in-house developed simulation program SunIrradiance. SunIrradiance enables the simulation of the whole PV chain from solar cells to PV systems. The SISIM model exhibits a far better simulation of the annual energy production in PV systems than the previously used spectral irradiation model. The hourly solar irradiation values simulated with the SISIM have a higher and more realistic annual irradiation intensity deviation than with the old BirdUpg model.

The new SISIM model was developed and verified for weather conditions in Ljubljana, Slovenia, but as Ljubljana is located in Central Europe, the model is valid also for any location in this region or even worldwide if the corresponding local input data are used.

\section{Conflict of Interests}

The authors declare that there is no conflict of interests regarding the publication of this paper.

\section{Acknowledgment}

The authors acknowledge the financial support of the Slovenian Research Agency (Research Programme P2-0197).

\section{References}

[1] B. Lipovšek, J. Krč, and M. Topič, "Optical model for thinfilm photovoltaic devices with large surface textures at the front side," Informacije MIDEM, vol. 41, no. 4, pp. 264-271, 2011.

[2] IEC 60904-3 Ed.2-PHOTOVOLTAIC DEVICES-part 3: measurement principles for terrestrial photovoltaic (PV), 2008.

[3] IEC 61215 Ed.2: crystalline silicon terrestrial photovoltaic (PV) modules- design qualification and type approval, design, 2005. 
[4] J. Kurnik, M. Jankovec, K. Brecl, and M. Topič, "Development of outdoor photovoltaic module monitoring system," Informacije MIDEM, vol. 38, no. 2, pp. 75-80, 2008.

[5] R. E. Bird and R. L. Hulstrom, A Simpilified Clear Sky Model for Direct and Diffuse Insolation on Horizontal Surfaces, 1981.

[6] C. A. Gueymard, "Clear-sky irradiance predictions for solar resource mapping and large-scale applications: improved validation methodology and detailed performance analysis of 18 broadband radiative models," Solar Energy, vol. 86, no. 8, pp. 2145-2169, 2012.

[7] C. A. Gueymard, "REST2: high-performance solar radiation model for cloudless-sky irradiance, illuminance, and photosynthetically active radiation-validation with a benchmark dataset," Solar Energy, vol. 82, no. 3, pp. 272-285, 2008.

[8] D. R. Myers, Cloudy Sky Version of Bird's Broadband Hourly Clear Sky Model, National Renewable Energy Laboratory, 1981.

[9] V. Badescu, "A new kind of cloudy sky model to compute instantaneous values of diffuse and global solar irradiance," Theoretical and Applied Climatology, vol. 72, no. 1-2, pp. 127-136, 2002.

[10] J. Kurnik, M. Jankovec, K. Brecl, and M. Topic, "Outdoor testing of PV module temperature and performance under different mounting and operational conditions," Solar Energy Materials and Solar Cells, vol. 95, no. 1, pp. 373-376, 2011.

[11] D. Kastelec, J. Rakovec, and K. Zakšek, Sončna energija v Sloveniji, Založba ZRC, ZRC SAZU, 2007.

[12] P. Ineichen and R. Perez, "A new airmass independent formulation for the linke turbidity coefficient," Solar Energy, vol. 73, no. 3, pp. 151-157, 2002.

[13] R. J. Aguiar, M. Collares-Pereira, and J. P. Conde, "Simple procedure for generating sequences of daily radiation values using a library of Markov transition matrices," Solar Energy, vol. 40, no. 3, pp. 269-279, 1988.

[14] J. Remund and S. Kunz, Meteonorm Handbook Part II: Theory, 2003.

[15] R. Aguiar and M. Collares-Pereira, "TAG: a time-dependent, autoregressive, Gaussian model for generating synthetic hourly radiation," Solar Energy, vol. 49, no. 3, pp. 167-174, 1992.

[16] E. L. Maxwell, A Qusi-Phisycal Model for Converting Hourly Global Horizontal to Direct Normal Insolation, 1987.

[17] A. Louche, G. Notton, P. Poggi, and G. Simonnot, "Correlations for direct normal and global horizontal irradiation on a French mediterranean site," Solar Energy, vol. 46, no. 4, pp. 261-266, 1991.

[18] D. T. Reindl, W. A. Beckman, and J. A. Duffie, "Diffuse fraction correlations," Solar Energy, vol. 45, no. 1, pp. 1-7, 1990.

[19] F. J. Batlles, M. A. Rubio, J. Tovar, F. J. Olmo, and L. AladosArboledas, "Empirical modeling of hourly direct irradiance by means of hourly global irradiance," Energy, vol. 25, no. 7, pp. 675-688, 2000.

[20] “Meteonorm 7," 2011, http://meteonorm.ch.

[21] R. Perez, P. Ineichen, R. Seals, J. Michalsky, and R. Stewart, "Modeling daylight availability and irradiance components from direct and global irradiance," Solar Energy, vol. 44, no. 5, pp. 271-289, 1990.

[22] "Slovenian Environment Agency," 2012, http://www.arso.gov.si/. 

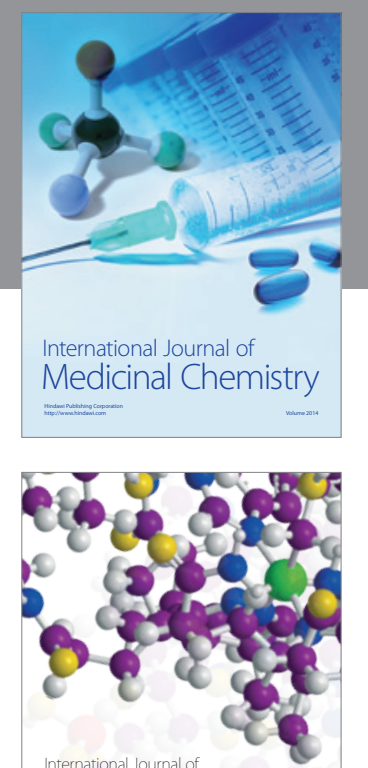

\section{Carbohydrate} Chemistry

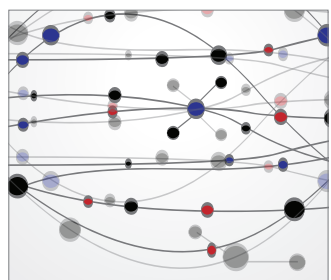

The Scientific World Journal
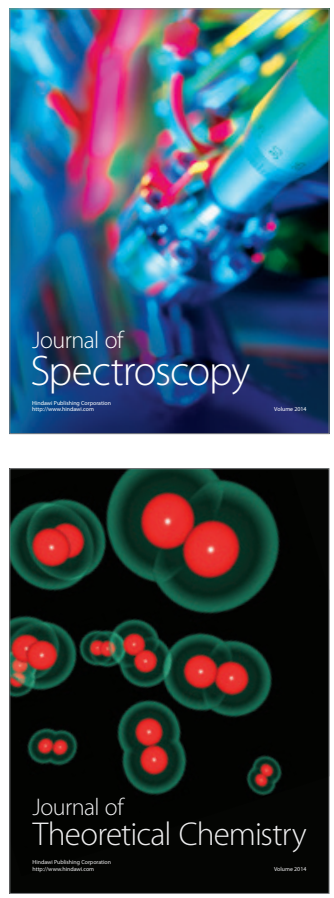
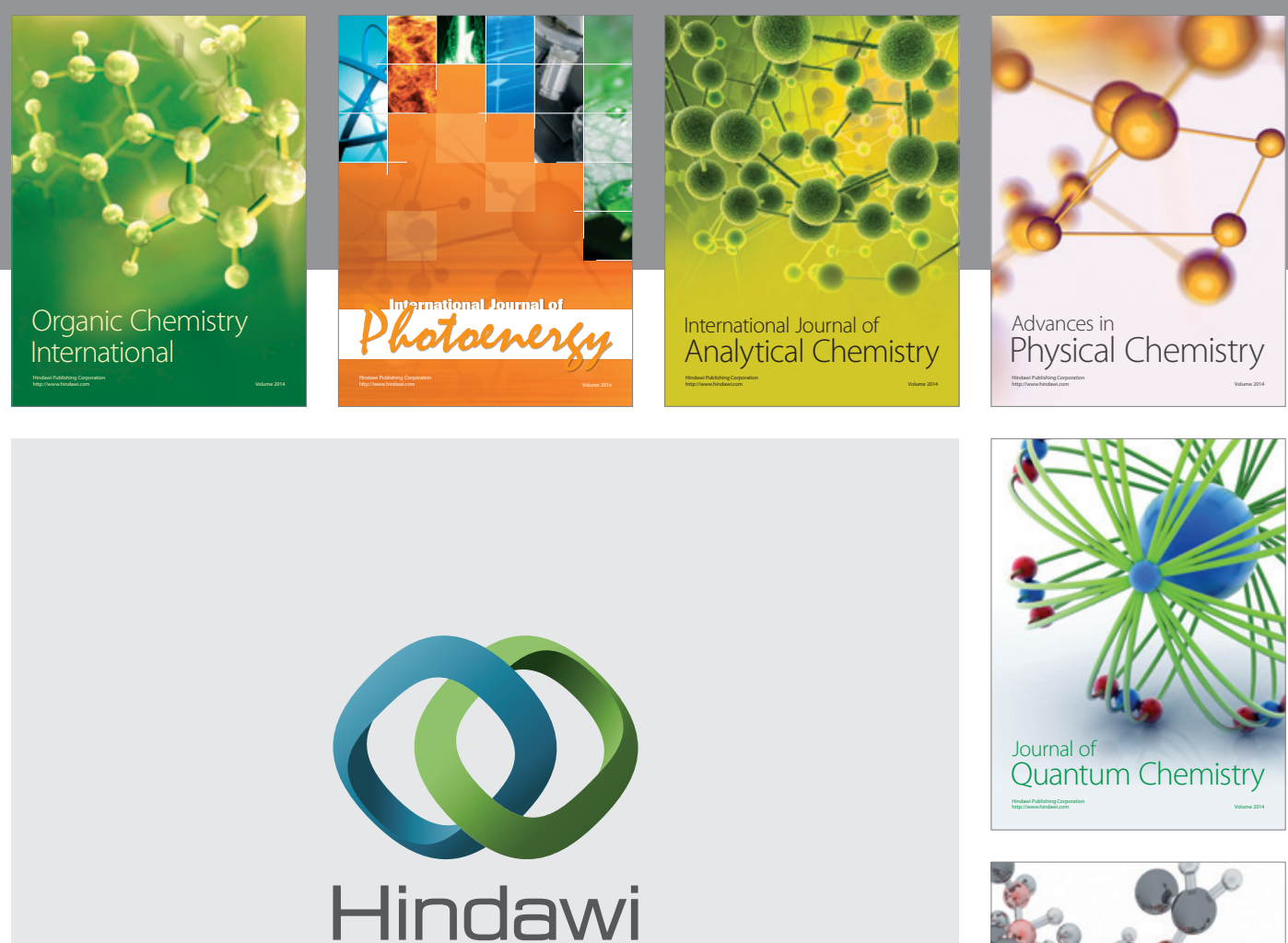

Submit your manuscripts at

http://www.hindawi.com

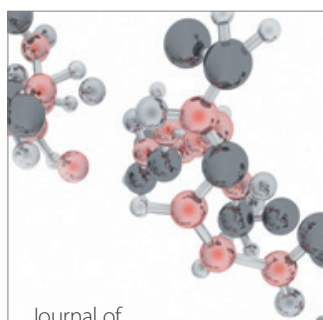

Analytical Methods

in Chemistry

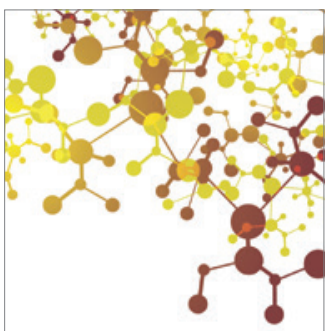

Journal of

Applied Chemistry

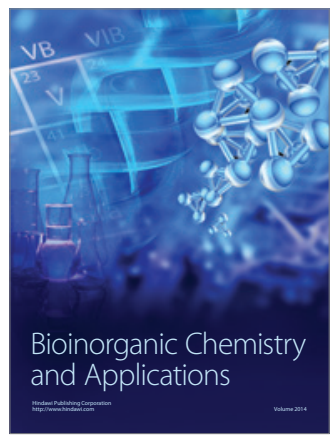

Inorganic Chemistry
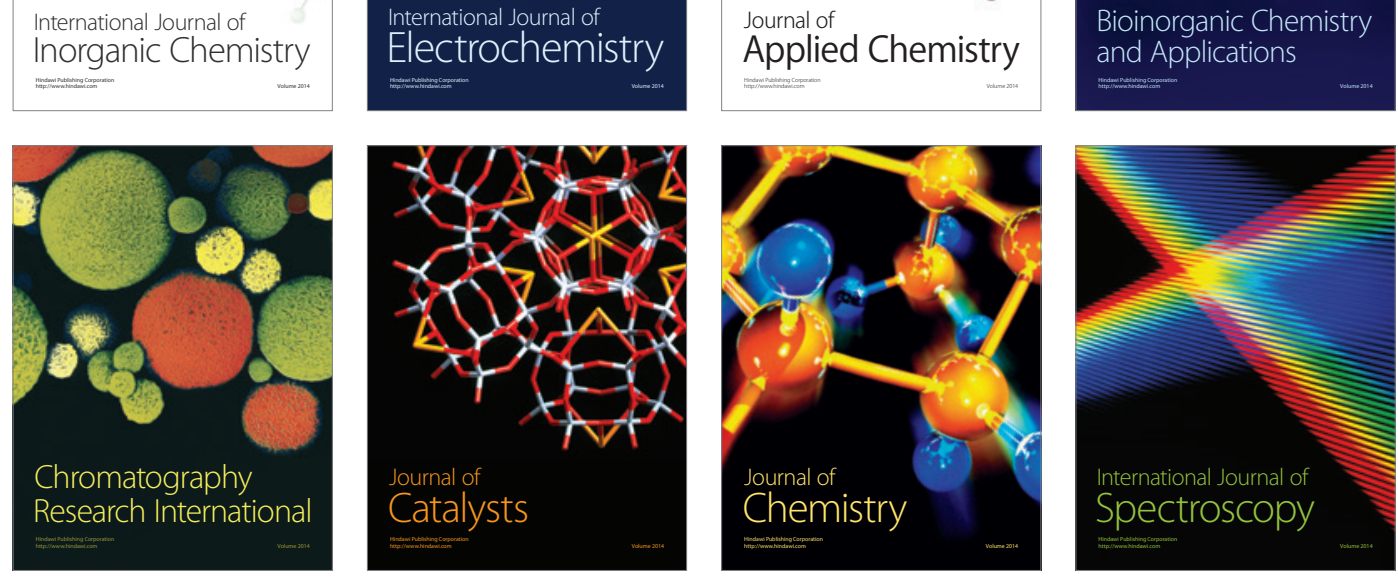